\title{
Effect of Additional Information on Consumer Acceptance: An Example with Pomegranate Juice and Green Tea Blends
}

\author{
Federica Higa, Kadri Koppel * and Edgar Chambers IV \\ Center for Sensory Analysis and Consumer Behavior, Kansas State University, Manhattan, KS 66502, USA; \\ Federica.higa@gmail.com (F.H.); eciv@ksu.edu (E.C.) \\ * Correspondence: kadri@ksu.edu; Tel.: +1-785-532-0163
}

Academic Editor: Miranda Mirosa

Received: 1 June 2017; Accepted: 27 June 2017; Published: 2 July 2017

\begin{abstract}
Pomegranate Juice (PJ) and Green Tea (GT) products have increased in popularity because of their beneficial health properties. Consumers look for healthier beverages, and rely on labels, claims, and product packaging when choosing a product. The objectives of this study were to determine (1) the sensory profiles and acceptance of PJ and GT blends; (2) whether additional information would have an effect on consumer acceptance; and (3) the total phenolic content (TPC) of the samples. Six PJ and GT blends were evaluated by a descriptive panel in order to explore sensory differences in flavor characteristics. A consumer panel $(n=100)$ evaluated the samples before and after beneficial health information about the samples was provided to them. The blends that were higher in tea concentration were higher in Green and GT-like flavors, and lower in berry, beet, floral, sweetness, and cherry flavors. The overall liking scores of all of the samples increased after the information was provided to the consumers. The sample highest in PJ and lowest in GT blend was liked the most. In addition, as the samples increased in PJ, the TPC content increased. These results may be of interest to the beverage industry, providing information of consumer liking of beverage blends, and how information on health related claims affects consumer acceptance.
\end{abstract}

Keywords: pomegranate juice; green tea; consumer; health; phenolic content

\section{Introduction}

Pomegranate Juice (PJ) has been reported to be the beverage with some of the highest antioxidant and phenolic content. The antioxidants content in PJ is higher than in black, green, or white tea, or red wines [1]. Due to its high phenolic content, several beneficial health related properties have been reported, such as cancer prevention, anti-inflammatory, antioxidant, and antibacterial properties, as well as being a facilitator of skin repair [2-5]. Pomegranate's popularity has increased, along with the consumption of healthy beverages in the world [6].

Previous studies have reported the influence of information on liking and purchase intent of several products, as well as consumer attitudes towards healthy food choices. Yoon et al. studied liking, emotional response, and the appropriate intensity of attributes of beverages when consumers were provided with information about the beverages, including nutritional information [7]. Further, Reale and Flint studied how providing nutritional information affected the selection of products on a menu, and showed that the graphical qualities rather than the specific information were more important [8]. Consumer attitudes toward product-related information are important factors to consider because they will determine the acceptance of food products, and the final decision of product purchase.

Previous studies have focused on Consumer Research, Descriptive, and Total Phenolic Content (TPC) of Pomegranates, or Green Tea (GT) either separately or mixed with other fruit juices, but no 
research has been found combining these two beverages. Koppel and Chambers developed a lexicon to describe the flavor of PJ [9]. Lee and Chambers established a lexicon for Green Tea [10], and further descriptive sensory studies have described GT's flavor from the samples of different countries [11,12]. Several consumer studies have been conducted to understand the liking of PJ [13-15] or GT samples, in the U.S. and across countries [16,17].

PJ has been mixed with other fruit juices such as black cherry and concord grapes [18], lemon juice [19], and berries juice [20] with the objective of obtaining blends with high antioxidant content, but no studies were found involving PJ and GT mixes. Studies determining the TPC and antioxidant content of PJ in the juice fraction obtained through different processes [21-25] found that juices pressed with the rind, membrane, and non-edible parts of the fruit had more TPC than those obtained from pressing only the fruit seeds.

The objectives of the present study were to determine (1) the sensory profiles and acceptance of pomegranate juice and green tea blends; (2) whether additional information would have an effect on consumer acceptance scores; and (3) the total phenolic content of the samples.

\section{Materials and Methods}

\subsection{Sample Preparation}

Fresh Wonderful Pomegranates from Del Rey, California (Pom Wonderful, LLC, Del Rey, CA, USA) were selected, washed, and squeezed using a manual fruit juicer (Jupiter Commercial Juice Press, Focus Foodservice, LLC, Lincolnshire, IL, USA). The fruits were cut in halves, and squeezed with the rind. They were later filtered using white basket paper coffee filters (Mellita USA Inc., Clearwater, FL, USA) to remove parts of the remaining membrane and albedo. Afterwards, they were frozen at $-26^{\circ} \mathrm{C}$ in a Standex BCF93558-0DX6 blast freezer (Standex, Salem, NH, USA) for $45 \mathrm{~min}$ in $946 \mathrm{~mL}$ Ziploc bags (SC Johnson, Racine, WI, USA), and stored at $-18{ }^{\circ} \mathrm{C}$ until used.

The PJ bags were thawed two days prior to evaluation, and one day before the preparation of the samples, and were stored in the refrigerator overnight until used.

Lipton Green tea (Unilever, Englewood Cliffs, NJ, USA) was purchased from a local grocery store at Manhattan, KS, USA. The tea was prepared according to the package's instructions for Quart Iced Tea: four tea bags were brewed in $473 \mathrm{~mL}$ of boiling water for $1.5 \mathrm{~min}$. After brewing, $710 \mathrm{~g}$ of ice cubes were added and allowed to melt completely. The samples were prepared at the following pomegranate juice (PJ)-green tea (GT) ratios: 90:10, 80:20, 70:30, 60:40, 50:50, and 40:60 $v / v$. the day before evaluation, and were refrigerated at $5{ }^{\circ} \mathrm{C}$.

\subsection{Descriptive Sensory Analysis}

\subsubsection{Sample Preparation}

A half-hour prior to panel evaluation, $30 \mathrm{~mL}$ of each sample was poured into $96 \mathrm{~mL}$ Styrofoam (Dart Container Corporation, Mason, MI, USA) lidded cups with four digit codes, and refrigerated until served at $5 \pm 1{ }^{\circ} \mathrm{C}$. More of each sample was available for tasting if requested.

\subsubsection{Panelists}

Six highly trained panelists from the Kansas State University Center for Sensory Analysis and Consumer Behavior (Manhattan, KS, USA) evaluated the six samples in triplicates in three $1.5 \mathrm{~h}$ sessions using attributes, definitions, and references from a Pomegranate Juice Lexicon developed by Koppel and Chambers [9] and a Green Tea Lexicon developed by Lee and Chambers [10].

All of the panelists had received $120 \mathrm{~h}$ of descriptive sensory analysis training, and had previous experience evaluating different beverages, including PJ. 


\subsubsection{Orientation and Evaluation}

During the orientation sessions, panelists were presented with the six samples and determined the attributes and references to be used. The final ballot was composed of 21 attributes (Table 1). The attributes Pomegranate ID, and Green Tea-like were added by the panel during the orientation sessions.

The samples were served monadically in a randomized order and evaluated individually using a scale ranging from 0 to 15 with 0.5 -point increments. The samples were evaluated in triplicates and six samples were evaluated in each session.

Unsalted crackers, deionized water, and cubed mozzarella cheese were used to clean palates between samples. Additionally, 10 min breaks were given after every two samples in order to cleanse palates and avoid carryover effect.

Table 1. Definition and Reference Attributes for the evaluation of the promegranate juice (PJ)-green tea (GT) blends.

\begin{tabular}{|c|c|c|}
\hline Attribute & Definition & Reference \\
\hline Pomegranate ID & $\begin{array}{l}\text { The sour, sweet, fruity aromatic that may be } \\
\text { somewhat dark, musty, earthy, with an } \\
\text { astringent mouthfeel. These aromatics are } \\
\text { reminiscent of a combination of fruits that } \\
\text { may or may not include concord grape, } \\
\text { cranberries, blackberries, raspberries, } \\
\text { cherries, currants, etc. There are also } \\
\text { vegetable notes of beets and carrots. }\end{array}$ & $\begin{array}{l}\text { Fresh pomegranate juice diluted }(1: 1)=3.5^{1} \\
\text { Preparation: Dilute fresh pomegranate } \\
\text { Juice } 1 \text { (juice): } 1 \text { (water). Serve in } 1 \mathrm{oz} \text { cup. }\end{array}$ \\
\hline Green tea-like & $\begin{array}{l}\text { A somewhat green, dusty, dried plant leaf } \\
\text { aromatic associated with green tea. }\end{array}$ & $\begin{array}{l}\text { Lipton Green tea. } \\
\text { Preparation: Brew tea following instructions for } \\
\text { preparing ice tea. }\end{array}$ \\
\hline Berry & $\begin{array}{l}\text { The sweet, sour, sometimes dark aromatics } \\
\text { associated with a variety of berries such as } \\
\text { blackberries, cherries, currants, raspberries, } \\
\text { etc., excluding cranberries. }\end{array}$ & Blackwell Red Currant Jelly = 8.5 \\
\hline Cranberry & $\begin{array}{l}\text { The sweet, fruity, slightly sour and sharp } \\
\text { aromatics commonly associated with } \\
\text { cranberries. }\end{array}$ & $\begin{array}{l}\text { Old Orchard's Frozen Cranberry diluted }(1: 1)=3.5 \\
\text { Ocean Spray Dried cranberries = 9.0 Preparation: } \\
\text { Reconstitute Cranberry Concentrate according to } \\
\text { instructions on the can. Dilute the reconstituted } \\
\text { cranberry juice } 1 \text { (juice): } 1 \text { (water) }\end{array}$ \\
\hline Cherry & $\begin{array}{l}\text { The sour, fruity, slightly bitter aromatics } \\
\text { commonly associated with cherries. }\end{array}$ & $\begin{array}{l}\text { RW Knudsen Cherry Juice diluted }(1: 2)=4.0 \\
\text { Preparation: Dilute the cherry juice } 1 \text { (juice): } 2 \text { (water), } \\
\text { serve in } 1 \mathrm{oz} \text { cup. }\end{array}$ \\
\hline Grape & $\begin{array}{l}\text { The sweet, brown, fruity, musty aromatics } \\
\text { commonly associated with grapes. }\end{array}$ & $\begin{array}{l}\text { Welch's Concord Grape Juice diluted }(1: 1)=5.0 \\
\text { Welch's White Grape Juice diluted }(1: 1)=5.0 \\
\text { Dilute grape juices } 1 \text { (juice): } 1 \text { (water), } \\
\text { serve in } 1 \text { oz. cup }\end{array}$ \\
\hline Floral & $\begin{array}{l}\text { An aromatic blend of a variety of fruits, } \\
\text { excluding citrus, cranberry, and concord } \\
\text { grape. May include apples, pears, white } \\
\text { grapes, etc. }\end{array}$ & $\begin{array}{l}\text { Welch's White Grape Juice diluted }(1: 1)=5.0 \\
\text { Dilute grape juice } 1 \text { (juice): } 1 \text { (water) }\end{array}$ \\
\hline Fruity & $\begin{array}{l}\text { An aromatic blend of a variety of fruits, } \\
\text { excluding citrus, cranberry, and concord } \\
\text { grape. May include apples, pears, white } \\
\text { grapes, etc. }\end{array}$ & $\begin{array}{l}\text { Welch's white grape juice diluted }(1: 1)=5.0 \\
\text { Dilute grape juice } 1 \text { (juice): } 1 \text { (water) }\end{array}$ \\
\hline Beet & $\begin{array}{l}\text { The damp, musty/earthy, slightly sweet } \\
\text { aromatics commonly associated with beets }\end{array}$ & $\begin{array}{l}\text { Diluted Kroger Canned Beet juice }(1: 2)=4.0 \\
\text { Preparation: Drain juice from beets. Dilute beet juice } \\
1 \text { (juice): } 2 \text { (water). }\end{array}$ \\
\hline Green & $\begin{array}{l}\text { Sharp, slightly pungent aromatics } \\
\text { associated with green plant/vegetable } \\
\text { matter, such as asparagus, Brussels sprouts, } \\
\text { celery, green beans, parsley, spinach, etc. }\end{array}$ & $\begin{array}{l}\text { Fresh Parsley water }=9.0 \text { (flavor) } \\
\text { Preparation: Weigh } 25 \mathrm{~g} \text { of fresh parsley, rinse, chop, } \\
\text { and add } 300 \mathrm{~mL} \text { of water. Let it sit for } 15 \mathrm{~min} . \\
\text { Filter and serve the liquid part. }\end{array}$ \\
\hline
\end{tabular}


Table 1. Cont.

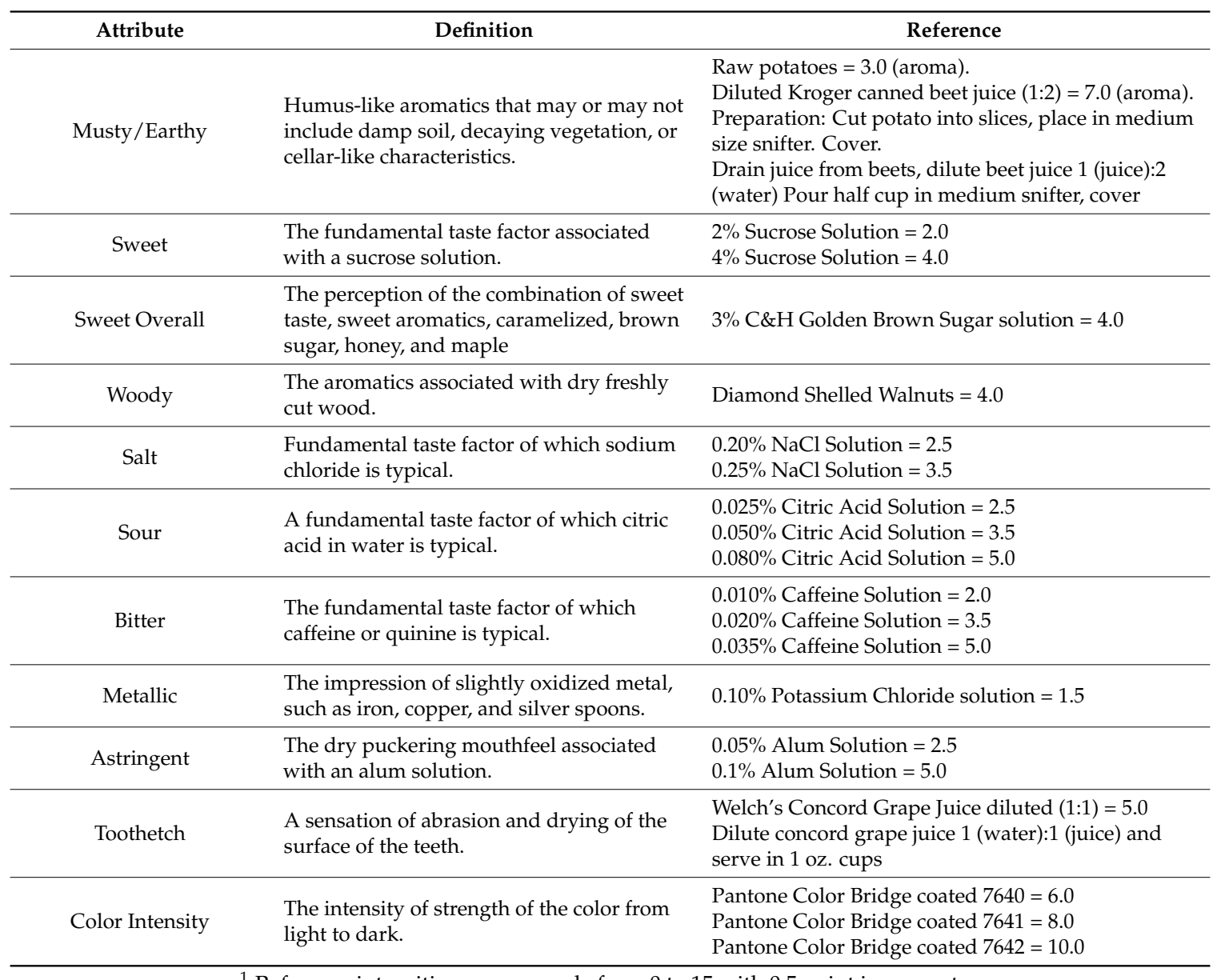

${ }^{1}$ Reference intensities are on a scale from 0 to 15 with 0.5 point increments.

\subsection{Consumer Research}

\subsubsection{Sample Preparation}

Samples were prepared as detailed in the Descriptive Sensory Analysis sample preparation section. A half-hour prior panel evaluation, $30 \mathrm{~mL}$ of each sample was poured into $96 \mathrm{~mL}$ Styrofoam lidded cups with four digit codes, and placed in refrigeration until served at $5 \pm 1{ }^{\circ} \mathrm{C}$.

\subsubsection{Consumers}

Consumers were recruited from the Center for Sensory Analysis and Consumer Behavior database (Manhattan, KS, USA) to participate in an evaluation of beverages study. The consumers were recruited, screened, and scheduled using RedJade software (RedJade ${ }^{\circledR}$, Redwood Shores, CA, USA). A total of 100 consumers participated in the study ( $66 \%$ women and $34 \%$ men, ages ranging from 18 to $>65$ years old, and income levels ranging from $<\$ 25,000$ to $>\$ 100,000$ per year). No pregnant or nursing women were included in the study; the consumers had to be over 18 years of age, and have no allergies or dietary restrictions. The consumers selected for the study reported that they consumed juice, iced tea, or juice-tea beverages at least once a week, and were willing to try a pomegranate-green tea flavor in a beverage.

The consumers received a confirmation e-mail that they had qualified for the study and a reminder e-mail the day before the test. 


\subsubsection{Test Design and Evaluation}

RedJade software (RedJade ${ }^{\circledR}$, Redwood Shores, CA, USA) was used to design the test, the questionnaires, and to collect data.

The samples were presented monadically, and the serving order was randomized to appear in each of the six possible positions. Unsalted crackers and purified water were provided for palate cleansing.

The test was carried out over a period of 5 days, with two or three sessions per day. A total of 100 consumers participated in the study, each attending one of the scheduled sessions.

At the beginning of the test, the consumers were presented with a consent form with general information about the test and participation in the study. Contact information for further questions was provided, and an electronic signature was collected.

Following this, general demographic questions were presented (age, gender, income), followed by a sample evaluation. The samples were served monadically in a randomized order, and the participants were asked to taste the samples and answer the presented questionnaire. Re-tasting of the samples was allowed as many times as necessary.

The consumers were asked about their Overall liking of the samples on a 9-point hedonic scale (1: dislike extremely, 5: neither like nor dislike, 9: like extremely), followed by questions about the Fruity Flavor, Tea Flavor, Sourness, Sweetness, and Color of the samples, rating on a 5-point Just about right scale (too little $=1$, too much $=5$ ). After the last sample was presented, the consumers were given general information on antioxidants and the Overall liking of the sample was asked again. This general information included the following statement:

Antioxidants are substances that protect cells from the damage caused by free radicals.

Free radicals may play a part in cancer, heart disease, stroke, and other diseases of aging.

(from www.cancer.gov). Antioxidants are found in several nuts, vegetables, and fruits such as Pomegranates, and herbs such as green tea. After reading this information on the beverage you just tasted, please indicate: how much do you LIKE or DISLIKE this sample OVERALL?

A similar approach has been used by Lawless et al. [18], who studied the effect of providing beneficial health related statements on a re-evaluation of the acceptance of black cherry, concord grape, and pomegranate juice blends.

\subsection{Total Phenolic Content (TPC) Determination}

\subsubsection{Samples}

PJ and GT blends were prepared following the steps in the Descriptive Analysis section the day prior to determination and were kept refrigerated at $5 \pm 1{ }^{\circ} \mathrm{C}$ until used. Unmixed Pomegranate Juice and Green Tea samples were also measured for TPC.

\subsubsection{Experimental Determination}

The Total Phenolic Content was determined using a modified spectrophotometric Folin-Ciocalteu method $[20,21,25]$.

Three milliliters $(3 \mathrm{~mL}$ ) of each sample was extracted with $3 \mathrm{~mL}$ of 95:5 Methanol (Sigma Aldrich, St. Louis, MO, USA): $\mathrm{HCl}$ (Sigma Aldrich, St. Louis, MO, USA) and left for one hour in the dark. The samples were centrifuged at $3000 \mathrm{rpm}$ for $15 \mathrm{~min}$ at $18^{\circ} \mathrm{C}$. The samples were resuspended with $3 \mathrm{~mL}$ of 95:5 Methanol: $\mathrm{HCl}$ and centrifuged again under the same conditions. Both supernatants were collected, since some sediment was present in the juice samples, and made up to $25 \mathrm{~mL}$ with double distilled water. Twenty milliliters $(20 \mathrm{~mL})$ was diluted with $1.58 \mathrm{~mL}$ of distilled water, $100 \mathrm{~mL}$ of Folin-Denis reagent (Sigma Aldrich, St. Louis, MO, USA), and $300 \mathrm{~mL}$ of a saturated sodium carbonate (Fisher Chemical, Bridgewater, NJ, USA) solution and measured at $750 \mathrm{~nm}$ in a spectrophotometer (Thermo Scientific GENESYS 10S, Thermo Electron Scientific Instruments LLC, Madison, WI, USA). 
A Gallic Acid (Fisher Chemical, Bridgewater, NJ, USA) standard curve was prepared following the same procedure as the samples. Measurements were run in triplicates.

\subsection{Data Analysis}

An Analysis of Variance (ANOVA) was performed to examine the differences in the descriptive attributes of the different PJ-GT samples at a 5\% level of significance. Panelists and repetition were considered random effects, while the sample was fixed. A post-hoc means comparison using Fisher's Protected LSD at a 5\% level of significance was performed to find differences in the samples.

The consumer data was analyzed using ANOVA at a 5\% level of significance, in order to explore differences in overall liking scores $(n=100)$ and the same analysis was run after the antioxidant information was provided for the last sample of the randomized serving set. The samples in the ratios of 40:60 and 90:10 were presented last in the serving set a total of 16 times, while the rest of the samples were presented last to consumers 17 times. A panelist was considered a random effect, while the sample was fixed.

An Agglomerative Hierarchical Cluster Analysis (AHC) was conducted to cluster consumers into different groups based on their overall liking scores, and ANOVA was run for each cluster. A post-hoc means comparison using Fisher's LSD at a 5\% level of significance was performed to find differences in the clusters.

Preference Mapping was run using both consumer and descriptive data in order to determine the drivers of liking of the samples.

All statistical analyses were performed using XLSTAT (Addinsoft, New York, NY, USA).

This study was approved (IRB approval \#8087) by the Internal Review Board at Kansas State University.

\section{Results}

\subsection{Descriptive Analysis}

The following 14 attributes were found to be significantly different $(p<0.05)$ among the samples: pomegranate ID, green tea-like, berry, cranberry, cherry, grape, floral, fruity, beet, green, sweet overall, sweet, bitter, and color intensity. As expected, as samples increased in PJ content, cherry, grape, floral, pomegranate ID, sweetness, sweetness overall, and color intensity attributes increased, while with increasing GT concentration, the samples showed higher green and green tea-like intensities, a lower color intensity, and lower beet and fruity flavor intensities (Table 2). Green and green tea-like flavors were found in all of the samples, but the intensities decreased as the PJ concentration rose.

Catechin content is the main responsible component of bitterness in green tea [10,26]; however, bitterness in the evaluated samples was found to be of low intensity, more similar to the PJ bitterness reported by Koppel et al. [25]. This may be explained by the higher content of PJ than GT in the samples.

The flavor attributes overall had weak intensities, lower than 4 points on a scale from 0 to 15 . Koppel et al. [25] obtained similar results when evaluating frozen, pasteurized, and dehydrated PJ samples by a descriptive panel.

Table 2. Mean intensity scores for PG-GT samples attributes. Means with different letters were significantly different $(p<0.05)$ using Fisher's LSD test.

\begin{tabular}{ccccccc}
\hline Sample Attribute & $\mathbf{9 0 / 1 0}$ & $\mathbf{8 0 / 2 0}$ & $\mathbf{7 0 / 3 0}$ & $\mathbf{6 0 / 4 0}$ & $\mathbf{5 0 / 5 0}$ & $\mathbf{4 0 / 6 0}$ \\
\hline Pomegranate ID & $3.61^{1} \mathrm{a}$ & $3.75 \mathrm{a}$ & $3.67 \mathrm{a}$ & $3.31 \mathrm{~b}$ & $2.81 \mathrm{c}$ & $2.58 \mathrm{c}$ \\
Green Tea-like & $2.19 \mathrm{~d}$ & $2.25 \mathrm{~d}$ & $2.53 \mathrm{c}$ & $2.58 \mathrm{c}$ & $2.83 \mathrm{~b}$ & $3.14 \mathrm{a}$ \\
Berry & $2.86 \mathrm{ab}$ & $2.92 \mathrm{a}$ & $2.67 \mathrm{bc}$ & $2.50 \mathrm{c}$ & $2.19 \mathrm{~d}$ & $1.92 \mathrm{e}$ \\
& $2.36 \mathrm{a}$ & $2.47 \mathrm{a}$ & $2.36 \mathrm{a}$ & $2.39 \mathrm{a}$ & $1.97 \mathrm{~b}$ & $2.00 \mathrm{~b}$ \\
\hline
\end{tabular}


Table 2. Cont.

\begin{tabular}{ccccccc}
\hline Sample Attribute & $\mathbf{9 0 / 1 0}$ & $\mathbf{8 0 / 2 0}$ & $\mathbf{7 0 / 3 0}$ & $\mathbf{6 0 / 4 0}$ & $\mathbf{5 0 / 5 0}$ & $\mathbf{4 0 / 6 0}$ \\
\hline Cranberry & $2.17 \mathrm{ab}$ & $2.25 \mathrm{a}$ & $2.11 \mathrm{ab}$ & $1.94 \mathrm{bc}$ & $1.75 \mathrm{c}$ & $1.36 \mathrm{~d}$ \\
Cherry & $1.86 \mathrm{ab}$ & $2.03 \mathrm{a}$ & $2.03 \mathrm{a}$ & $1.69 \mathrm{bc}$ & $1.50 \mathrm{~cd}$ & $1.31 \mathrm{~d}$ \\
Grape & $2.42 \mathrm{a}$ & $2.47 \mathrm{a}$ & $2.44 \mathrm{a}$ & $2.36 \mathrm{a}$ & $2.14 \mathrm{~b}$ & $1.92 \mathrm{c}$ \\
Floral & $2.81 \mathrm{ab}$ & $2.89 \mathrm{a}$ & $2.75 \mathrm{ab}$ & $2.64 \mathrm{~b}$ & $2.36 \mathrm{c}$ & $2.17 \mathrm{c}$ \\
Fruity & 1.47 & 1.50 & 1.36 & 1.22 & 1.22 & 1.14 \\
Beet & 1.86 & 1.944 & 2.06 & 2.03 & 2.08 & 2.31 \\
Green & 1.97 & 2.03 & 2.00 & 1.92 & 1.83 & 1.86 \\
Musty/Earthy & $3.61 \mathrm{a}$ & $3.75 \mathrm{a}$ & $3.67 \mathrm{a}$ & $3.31 \mathrm{~b}$ & $2.81 \mathrm{c}$ & $2.58 \mathrm{c}$ \\
Woody & 1.83 & 1.86 & 1.92 & 1.89 & 1.83 & 1.86 \\
Sweet Overall & $3.08 \mathrm{a}$ & $3.11 \mathrm{a}$ & $2.92 \mathrm{ab}$ & $2.78 \mathrm{bc}$ & $2.56 \mathrm{~cd}$ & $2.38 \mathrm{~d}$ \\
Sweet & $2.58 \mathrm{a}$ & $2.50 \mathrm{a}$ & $2.39 \mathrm{ab}$ & $2.28 \mathrm{~b}$ & $2.19 \mathrm{~b}$ & $1.88 \mathrm{c}$ \\
Salt & 1.86 & 1.89 & 1.83 & 1.72 & 1.72 & 1.72 \\
Sour & 2.56 & 2.64 & 2.56 & 2.53 & 2.56 & 2.58 \\
Bitter & 3.00 & 2.89 & 2.81 & 2.83 & 2.89 & 3.14 \\
Metallic & 0.86 & 0.83 & 0.69 & 0.89 & 0.86 & 1.00 \\
Astringent & 2.92 & 2.86 & 3.00 & 2.81 & 2.92 & 3.00 \\
Toothetch & 2.31 & 2.25 & 2.29 & 2.06 & 2.06 & 2.22 \\
Color Intensity & $12.06 \mathrm{a}$ & $11.58 \mathrm{~b}$ & $10.86 \mathrm{c}$ & $9.75 \mathrm{~d}$ & $8.72 \mathrm{e}$ & $8.25 \mathrm{f}$ \\
\hline
\end{tabular}

${ }^{1}$ All intensities were measured on a scale from 0 to 15 with 0.5 point increments.

\subsection{Consumer Research}

The overall liking of samples showed that as the GT concentration increased, the overall liking decreased (Figure 1). The sample of ratio 90:10 was the most liked, with an average overall liking of 6.5, while the least liked sample was the one with the highest GT concentration (40:60).

The consumers were asked to re-score their overall liking after the antioxidant information was provided to them. The mean scores for all of the samples increased as a result of this (Figure 1). These results are also in line with Lawless et al. [18], where different juice blends were evaluated and health related information was provided before and after the tasting of the products. Tuorila et al. [27] reported that providing verbal information increased the acceptance of novel and familiar foods.

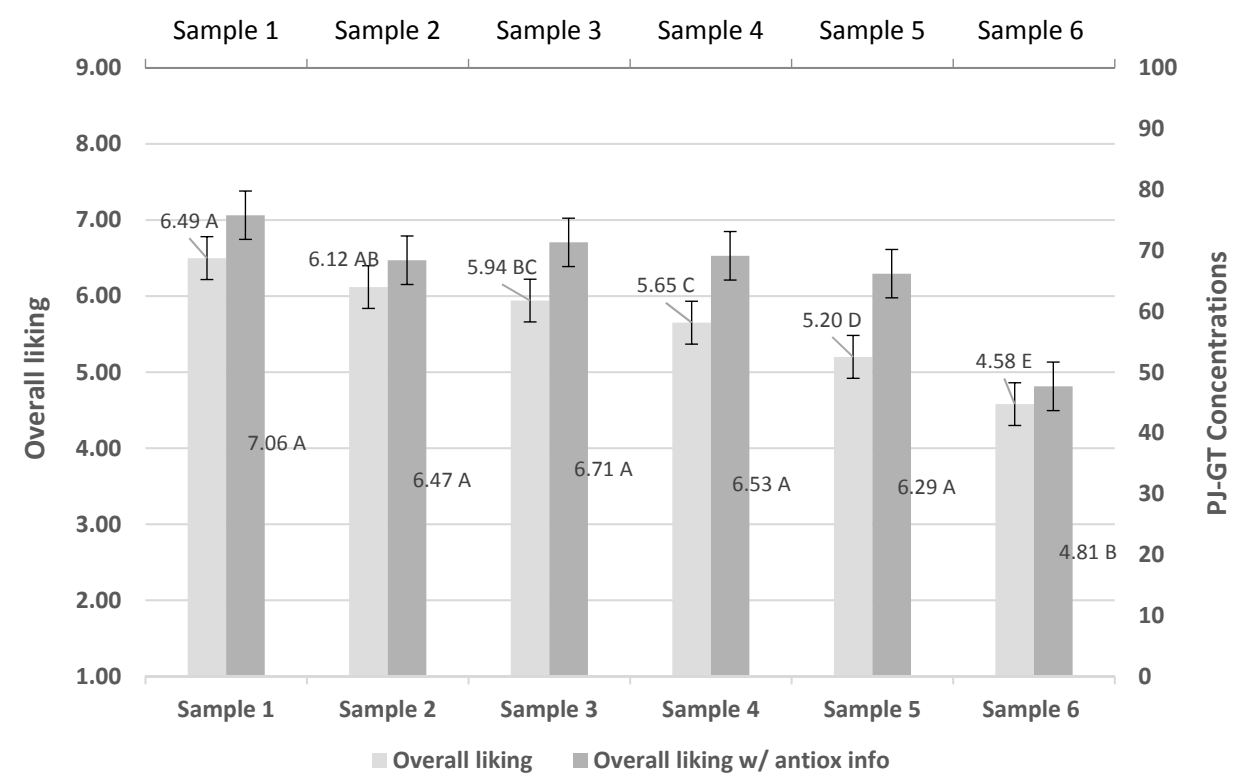

Figure 1. Mean scores for Overall Liking (scale 1: dislike extremely, 9: like extremely), evaluated before $(n=100)$ and after $(n=16$ for samples 40:60 and 90:10 and $n=17$ for samples 80:20, 70:30, 60:40, and 50:50) the antioxidant information was provided, compared to the samples' PJ and GT content (scale on the right $0-100 \%)$. The samples with different letters were significantly different $(p<0.05)$ following Fisher's LSD significant differences. 


\subsubsection{Preference Mapping}

A Preference Mapping (Figure 2) was performed to visualize how the different samples were related to the descriptive attributes, and to determine the drivers of overall liking of the samples. Dimension 1 accounted for $71.19 \%$ of the variability, and it can be explained with attributes bitter, astringent, and toothetch attributes, while Dimension 2 with $10.83 \%$ of the variation was correlated with sweet, berry, pomegranate ID, fruity, grape, sweet overall, cranberry, cherry, floral, green tea-like, and metallic attributes.

The sweet, sweet overall, floral, and fruity attributes such as pomegranate ID, berry, grape, cherry, and cranberry were the main drivers of liking the samples. This was consistent with the high overall liking scores of the samples of ratios 90:10, 80:20, and 70:30. The green, green tea-like, and metallic attributes were negatively correlated with consumer liking of the samples. Samples higher in these attributes, such as sample 40:60 and 50:50, were the least liked ones, and were perceived to be too low in sweetness and fruity flavor.

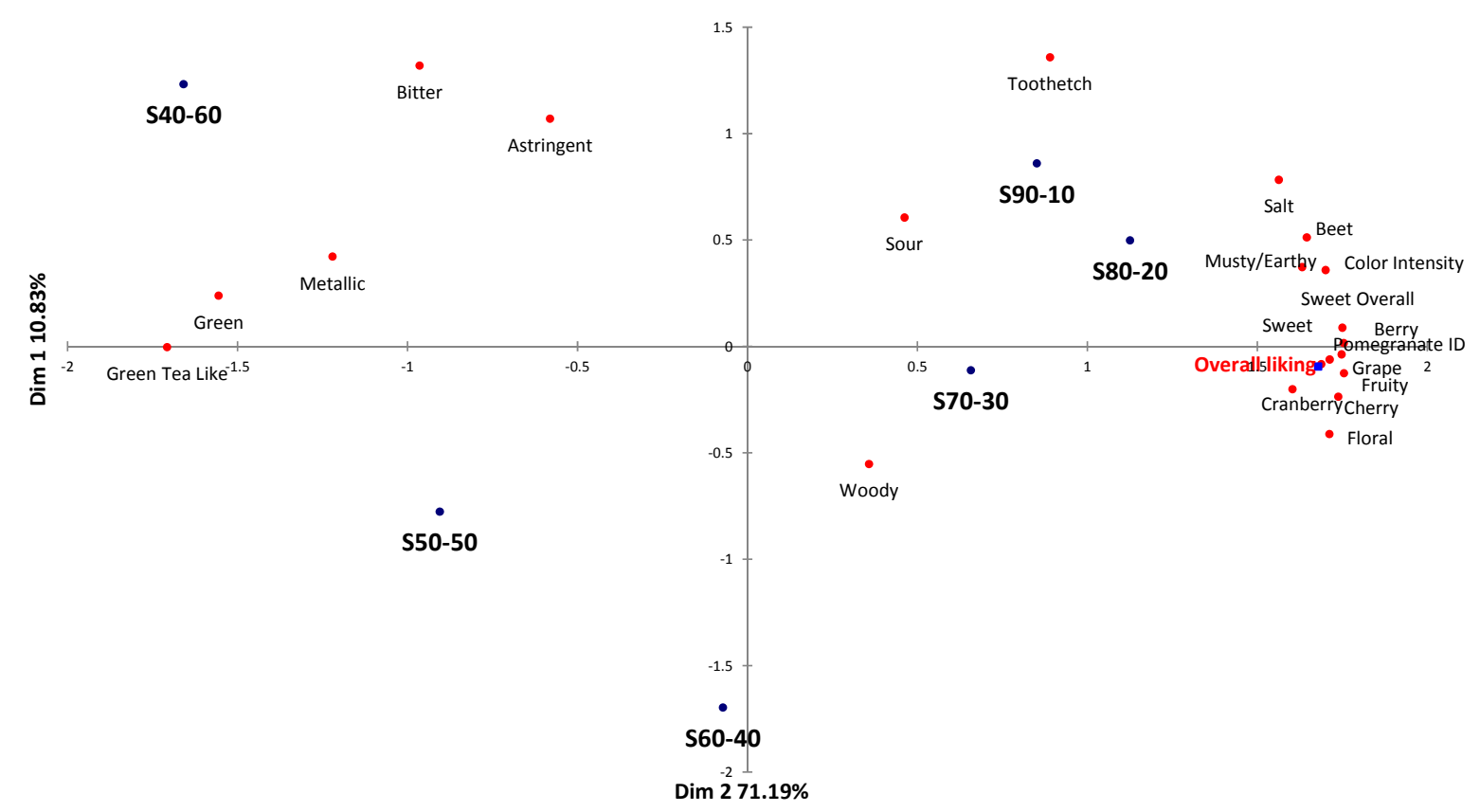

Figure 2. Preference Mapping of samples with dimensions 1 and 2 for the six PJ-GT samples and 21 descriptive attributes.

\subsubsection{Cluster Analysis}

A cluster analysis (Figure 3) was performed and three consumer clusters were found. The demographics were similar for the three clusters. Cluster 1 , composed by the majority of the consumers ( $n=44,22 \%$ females and $18 \%$ males) and the highest percentage of participants in the 55-64 age range, liked samples 80:20 and 90:10 and disliked sample 40:60. The overall liking scores for this cluster were higher than for the other two clusters. Cluster 2 ( $n=30,25 \%$ females and $8 \%$ males) disliked samples higher in GT concentration: 50:50 and 40:60, but liked sample 90:10 slightly. This cluster had the lowest percentage of participants in the 18-24 and 35-44 age ranges. Participants in Cluster 3 ( $n=26,18 \%$ females and 10\% males), liked sample 50:50 and gave the highest scores for the samples with a higher GT concentration. This cluster did not have participants of 65 years or over. Clusters 1 and 2 had also a low percentage of consumers in this age range ( $5 \%$ and $3 \%$, respectively). All three clusters had the majority of participants with an annual income of 51,000 to 100,000 dollars. These results indicate that while the majority of consumers liked samples higher in PJ better, there were some consumers who liked the samples higher in GT as well. 


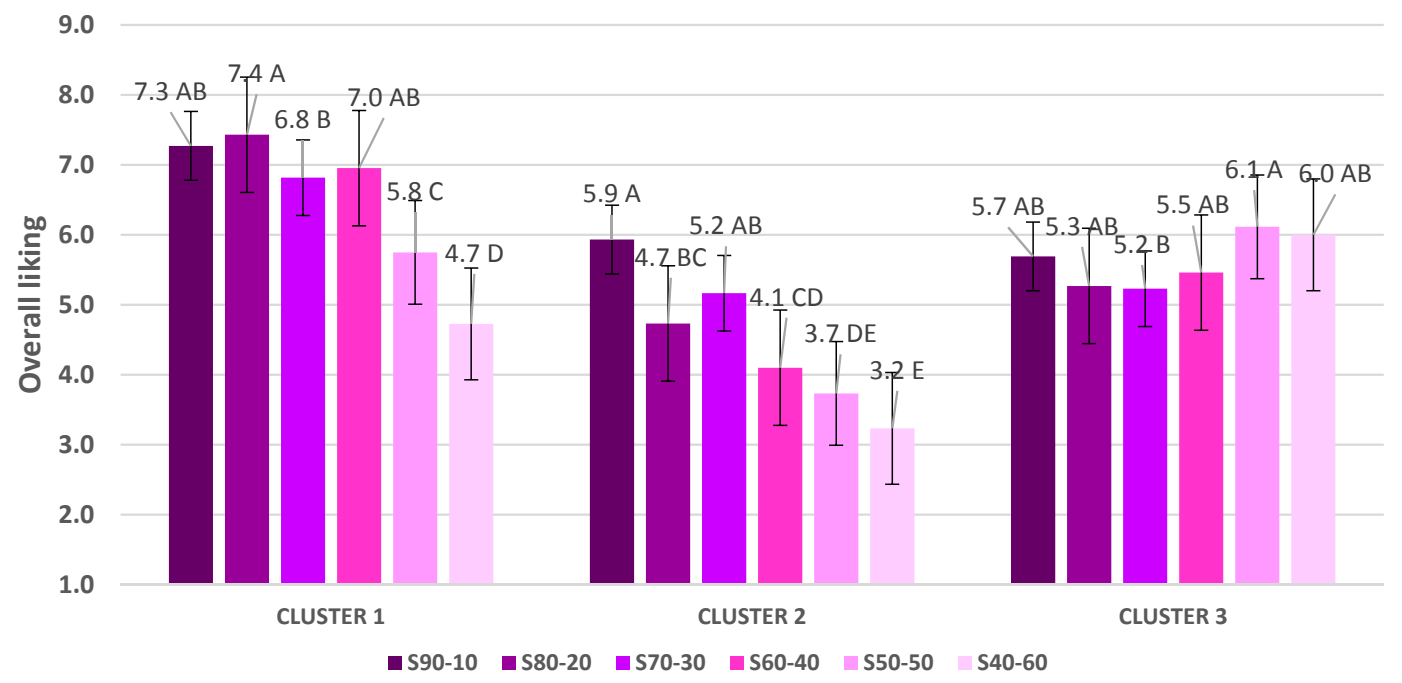

Figure 3. Mean Overall liking by Cluster $1(n=44)$, Cluster $2(n=30)$, and Cluster $3(n=26)$ for each sample (S90-10, S80-20, S70-30, S60-40, S50-50 and S40-60 correspond to each sample of PJ and GT concentrations respectively). Samples with different letters were significantly different $(p<0.05)$ following Fisher's LSD significant differences.

\subsection{Total Phenolic Content of Pomegranate Juice and Green Tea Blends}

The TPC of the samples varied from 697.4 to $2450.3 \mathrm{mg} / \mathrm{L}$ Gallic acid. Other studies have reported similar results $[21,23,28]$.

It was found that the highest sample in TPC was 100\% PJ. These results were found to be similar to those reported by other authors with the same juice extraction methods $[20,24]$. With an increasing GT ratio, the samples showed decreasing TPC. Plain GT had the lowest TPC (Table 3). These results showed that the higher phenolic content increased overall liking. However, these results also can be attributed to the sweetness and the fruity flavor of the samples higher in PJ.

The TPC of the mixtures showed to be the sum of the TPC of the individual GT and PJ components. Similar results were obtained by González-Molina et al. [19] where mixtures of $25 \%, 50 \%$, and $75 \%$ of PJ and lemon juice reported that the TPC values were the sum of the TPC of each component separately.

The TPC from the PJ in this study was found to be higher than those obtained from juice prepared with arils only [25]. Gil et al. [24] reported the antioxidant activity of different PJ extraction methods, and juice extracted by pressing the fruit with the rind showed higher TPC and antioxidant results than those prepared using only seeds.

The Folin method has been reported to have some interferences in the determination, such as the presence of ascorbic acid [29], and as a result errors can occur in the determination of the samples' total phenolic content. However, Sandström [30] reported that the method's results are reliable if juices of the same type or fruit are determined, in this case comparison among Pomegranate juices.

Table 3. Total Phenolic Content (TPC) in the PJ and GT blends.

\begin{tabular}{cc}
\hline Sample & TPC $(\mathbf{m g}$ Gallic Acid Equivalents/L \pm Stdev) \\
\hline Tea & $697.436 \pm 0.003$ \\
$40: 60$ & $1312.821 \pm 0.003$ \\
$50: 50$ & $1564.569 \pm 0.008$ \\
$60: 40$ & $1802.331 \pm 0.003$ \\
$70: 30$ & $1960.839 \pm 0.005$ \\
$80: 20$ & $2091.375 \pm 0.009$ \\
$90: 10$ & $2310.490 \pm 0.013$ \\
Juice & $2450.350 \pm 0.009$ \\
\hline
\end{tabular}




\section{Discussion}

A descriptive sensory panel determined the flavor characteristics evaluated in six PJ-GT blends at different ratios, and a consumer panel of juice and tea drinkers assessed the overall liking of the samples before and after antioxidant information was provided. A descriptive analysis on the samples showed higher intensities of juice related attributes for samples higher in Pomegranate Juice. Green was the only attribute present that was related to a previously developed Green Tea lexicon. The overall liking was higher for samples with higher juice ratios. These samples were higher in sweetness, fruity, berry, pomegranate ID, cherry, and grape flavors, and low in green tea-like, green, bitter, and astringent attributes. Consumer clusters indicated, however, that there may be a segment of consumers who like the samples higher in GT as well. These results indicate that further research with these types of fruit-beverage blends may be necessary.

In this study, beneficial health information of the product had a positive influence on the overall liking of the samples. This indicated that providing additional information about the product can be a positive marketing approach. In previous studies, Coleman et al. [7] investigated liking, emotional response, and purchase intent on prebiotic enriched breads and the impact of claims through a consumer test with identical samples with different claims. Two clusters were found: Cluster 1 was not accepting of the claims, and their purchase intent diminished when products presented claims, while Cluster 2 was the opposite, and besides being more accepting, their purchase intent increased if the product presented claims. The overall liking of the samples did not change when claim information was presented. However, the consumers stated that many of the claims were not easy to understand, and questioned the truthiness of the claims.

In a different study, Liem et al. [31] looked at how labels affected the taste perception of different formulations of reduced sodium soups. Participants rated the expected saltiness before tasting and the liking of the samples. They were able to add salt after tasting if desired. The findings of the study showed that samples with labels stating a salt reduction were negatively received and increased the difference between the expected and the actual saltiness of the product. As a result, salt expectation and liking were low, therefore consumers tended to add more salt to the samples.

Lawless et al. [18] found that in a mixture design, Concord grape flavor was liked better than black cherry or pomegranate juice flavors, and that carried through after additional information on the antioxidant content was provided to the consumers. This was not the case in the current study, however, where PJ-GT mixtures that were high in PJ were liked better than the mixtures high in GT, and additional information actually increased the overall liking scores.

Health claims had a positive effect on consumer acceptance of two different concentrations of acaí juices, at $4 \%$ and $40 \%$ [32]. The overall mean liking scores were higher for the $40 \%$ concentration juice. However, the $4 \%$ acai juice had higher scores than the $40 \%$ juice before and after information was provided to consumers, suggesting that the acceptance of a product is more influenced on sensory liking rather than the health claims of the products. Tourila et al. [27] reported that providing verbal information increased the acceptance of novel and familiar foods.

Kihlberg et al. [33] found that providing health related information to consumers affected their liking responses in a study conducted where health effect and ingredient origin were presented in different bread samples. The authors found that liking of three out of four samples was increased when health information was provided. Clearly, ingredient and flavor combinations as well as the information provided have a significant effect on consumer acceptance.

The TPC determinations showed that the mixtures of PJ and GT were the sum of their individual TPC content, and that the results accorded to those previously reported by other authors. The results from the TPC of GT were similar to those reported by Astill et al. [34], who prepared the samples using an aqueous extract and with no agitation following the product's package instructions as in the present study. Astill et al. [34] reported several factors that affect the polyphenols extracted from tea infusions: the particle size of the leaves, manufacturing, variety, the growing conditions and brewing method (loose leaves, tea bags, and tea bag material), the amount and temperature of the water, and agitation. 
For the agitation of the tea bag, higher brewing times and temperatures increase the extraction of chemicals in the liquid, and the material of the bag will determine the ease of the soluble components to be transported to the outside liquid, as well as the leaf to water ratio, where lower ratios allow a higher extraction of soluble compounds. It also needs to be taken into account that in Asian countries where drinking GT is very common, the first brew is sometimes discarded, and the same leaves are used for multiple brews [34-36]. The discarded portion would be the one containing the highest polyphenol content.

Lee et al. [17] found that of several green tea samples from different countries, Lipton green tea, characterized by green, brown, straw-like, and bitter flavor characteristics, was among the liked samples for U.S. consumers. However, the mean overall liking score for this sample was 5.69 on a 9-point hedonic scale, which translates into a bit higher score than "neither like nor dislike". The results from this current study confirmed relatively low overall liking scores for samples higher in GT. This may indicate that green tea for consumers in the U.S. is generally a category that is not evaluated highly for overall liking, but is rather consumed for its health-related and invigorating properties.

Lee and Chambers [12] studied flavor changes when variables such as brewing times and water temperature changed, and found that higher temperatures resulted in more bitter, astringent, and toothetch flavors. Longer brewing times also provided higher intensities in seaweed flavor. The samples in this study were all brewed following a single procedure. However, factors influencing flavor must be taken into account depending upon the desired characteristics of the product. For example, higher brewing times will result in higher Total Phenolic Content (TPC), but will also result in a beverage higher in bitterness. This may not be liked by the consumers of the resulting product.

There are some limitations to this study. The effect of added information was studied only for PJ-GT blends and with the addition of one specific form of health information to the last sample evaluated. This reduced the number of consumers who evaluated a single sample for additional health information effects significantly. Further studies might consider investigating different health effects as well as different products. It would also be interesting to develop a reverse version of the blends, that means ratios higher in tea, and enriched with Pomegranate juice, in order to increase the likeability of tea and enhance its health properties, given that PJ has higher TPC content than GT, as well as adding value to GT, which is a product that has a considerably lower cost than PJ. In addition, the consumers in the current study only had a limited amount of sample to consume. Future research may need to evaluate consumer attitudes after a larger quantity of a PJ-GT mixture has been consumed. The consumer study was conducted in Manhattan, Kansas, USA, and while these consumers represent local juice drinkers, future research may want to include consumers from other areas and perhaps other countries as well.

Acknowledgments: The authors would like to thank Faris Hussain for his help in determining the Total Phenolic content of the samples.

Author Contributions: Kadri Koppel, Federica Higa, and Edgar Chambers IV conceived and designed the experiments; Federica Higa performed the experiments; Federica Higa and Kadri Koppel analyzed the data; Federica Higa wrote the manuscript; Kadri Koppel and Edgar Chambers IV edited the manuscript.

Conflicts of Interest: The authors declare no conflict of interest.

\section{References}

1. Seeram, N.P.; Aviram, M.; Zhang, G.Y.; Henning, S.; Feng, L.; Dreher, M.; Heber, D. Comparison of Antioxidant Potency of Commonly Consumed Polyphenol-Rich Beverages in the United States. J. Agric. Food Chem. 2008, 56, 1415-1422. [CrossRef] [PubMed]

2. Kim, N.D.; Mehta, A.R.; Yu, W.; Neeman, I.; Livne, Y.T.; Amichay, A.; Poirier, D.; Nicholls, P.; Kirby, A.; Jinag, W.; et al. Chemopreventive and adjuvant therapeutic potential of pomegranate (Punica Granatum) for human breast cancer. Breast Cancer Res. Treat. 2002, 71, 203-217. [CrossRef] [PubMed] 
3. Aslam, M.N.; Lansky, E.P.; Varani, J. Pomegranate as a cosmeceutical source: Pomegranate fractions promote proliferation and procollagen synthesis and inhibit matrix metalloproteinase-1 production in human skin cells. J. Ethnopharmacol. 2006, 103, 311-318. [CrossRef] [PubMed]

4. Naz, S.; Siddiqui, R.; Ahmad, S.; Rasool, S.A.; Sayeed, S.A. Antibacterial Activity Directed Isolation of Compounds from Punica Granatum. J. Food Sci. 2007, 72, 341-345. [CrossRef] [PubMed]

5. Panichayupakaranant, P.; Tewtrakul, S.; Yuenyongsawad, S. Antibacterial, anti-inflammatory and anti-allergic activities of standardized pomegranate rind extract. Food Chem. 2010, 123, 400-403. [CrossRef]

6. Fuhrman, E. A Wonderful World: Pom Wonderful takes Pomegranates to places it has never gone before (cover story). Beverage Ind. 2008, 99, 16-22.

7. Yoon, E.; Kim, J.; Lee, J. The U.S. consumers' acceptability and emotion measures when consuming novel Korean traditional non-alcoholic beverages. J. Sens. Stud. 2016, 31, 256-271. [CrossRef]

8. Reale, S.; Flint, S.W. The impact of menu label design on visual attention, food choice and recognition: An eye tracking study. J. Sens. Stud. 2016, 31, 328-340. [CrossRef]

9. Koppel, K.; Chambers, E., IV. Development and Application of a Lexicon to Describe the Flavor of Pomegranate Juice. J. Sens. Stud. 2010, 25, 819-837. [CrossRef]

10. Lee, J.; Chambers, D. A Lexicon for Flavor Descriptive Analysis of Green Tea. J. Sens. Stud. 2007, $22,256-272$. [CrossRef]

11. Lee, J.; Chambers, D.; Chambers, E., IV. A comparison of the flavor of green teas from around the world. J. Sci. Food Agric. 2013, 94, 1315-1324. [CrossRef] [PubMed]

12. Lee, J.; Chambers, D. Sensory descriptive evaluation: Brewing methods affect flavor of green tea. Asian J. Food Agro-Ind. 2009, 2, 427-439.

13. Koppel, K.; Chambers, E., IV; Vazquez-Araujo, L.; Timberg, L.; Carbonell-Barrachina, A.A.; Suwonsichon, S. Cross Country comparison of pomegranate juice acceptance in Estonia, Spain, Thailand, and United States. Food Qual. Preference 2014, 31, 116-123. [CrossRef]

14. Anderson, E.; Koppel, K.; Chambers, E., IV. Consumer Evaluation of Processing Variants of Pomegranate Juice. Beverages 2015, 1, 3-16. [CrossRef]

15. Carbonell-Barrachina, A.A.; Calin-Sanchez, A.; Bagatar, B.; Hernandez, F.; Legua, P.; Martinez-Font, R.; Melgarejo, P. Potential of Spanish sour-sweet pomegranates (cultivar C25) for the juice industry. Food Sci. Technol. Int. 2011, 18, 129-138. [CrossRef] [PubMed]

16. Lee, J.; Chambers, D. Descriptive Analysis and U.S. Consumer Acceptability of 5 Green Tea Samples from China, Japan, and Korea. J. Food Sci. 2010, 75, 141-147. [CrossRef] [PubMed]

17. Lee, J.; Chambers, E., IV; Chambers, D.; Chun, S.S.; Oupadissakoon, G.; Johnson, D.E. Consumer acceptance for green tea by consumers in the United States, Korea and Thailand. J. Sens. Stud. 2010, 25, 109-132.

18. Lawless, L.J.R.; Threlfall, R.T.; Meullenet, J.F.; Howard, L.R. Applying a Mixture Design for Consumer Optimization of Black Cherry, Concord Grape and Pomegranate Juice Blends. J. Sens. Stud. 2013, 28, 102-112. [CrossRef]

19. Gonzales-Molina, E.; Moreno, D.A.; GarciaViguera, C. A new drink rich in healthy bioactives combining lemon and pomegranate juices. Food Chem. 2009, 115, 1364-1372. [CrossRef]

20. Vazquez-Araujo, L.; Chambers, E., IV; Adhikari, K.; Carbonell-Barrachina, A.A. Sensory and Physicochemical Characterization of Juices Made with Pomegranate and Blueberries, Blackberries, or Raspberries. J. Food Sci. 2010, 75, 398-404. [CrossRef] [PubMed]

21. Tezcan, F.; Gultekin-Ozguven, G.; Diken, T.; Ozcelik, B.; Erim, F.B. Antioxidant activity and total phenolic, organic acid and sugar content in commercial pomegranate juices. Food Chem. 2009, 115, 873-877. [CrossRef]

22. Tzulker, R.; Glazer, I.; Bar-Ilan, I.; Holland, D.; Aviram, M.; Amir, R. Antioxidant Activity, Polyphenol Content, and Related Compounds in Different Fruit Juices and Homogenates Prepared from 29 Different Pomegranate Accessions. J. Agric. Food Chem. 2007, 55, 9559-9570. [CrossRef] [PubMed]

23. Vazquez-Araujo, L.; Chambers, E., IV; Adhikari, K.; Carbonell-barrachina, A.A. Physico-chemical and sensory properties of pomegranate juices with pomegranate albedo and carpellar membranes homogenate. Food Sci. Technol. 2011, 44, 2119-2125.

24. Gil, M.I.; TomasBarberan, F.A.; Hess, B. Antioxidant Activity of Pomegranate Juice and Its Relationship with Phenolic Composition and Processing. J. Agric. Food Chem. 2000, 48, 4581-4589. [CrossRef] [PubMed]

25. Koppel, K.; Anderson, E.L.; Chambers, E., IV. Influence of processing on pomegranate (Punicagranatum L.) juice flavor and aroma. J. Sci. Food Agric. 2014, 95, 1066-1071. [CrossRef] [PubMed] 
26. Senanayake, N. Green Tea extracts: Chemistry, antioxidant properties and food applications-A Review. Funct. Foods 2013, 5, 1529-1541. [CrossRef]

27. Tuorila, H.; Meiselman, H.L.; Bell, R.; Cardello, O.A.V.; Johnson, W. Role of Sensory and Cognitive Information in the Enhancement of Certainty and Liking for Novel and Familiar Foods. Appetite 1994, 23, 231-246. [CrossRef] [PubMed]

28. Turkyilmaz, M.; Tagi, S.; Dereli, U.; Ozkan, M. Effects of various pressing programs and yields on the antioxidant activity, antimicrobial activity, phenolic content and colour of pomegranate juices. Food Chem. 2013, 138, 1810-1818. [CrossRef] [PubMed]

29. Lester, G.E.; Lewers, K.; Medina, M.; Saftner, R. Comparative analysis of strawberry total phenolics via Fast Blue BB vs. Folin-Ciocalteau: Assay interference by ascorbic acid. J. Food Comp. Anal. 2012, 27, 102-107. [CrossRef]

30. Sandström, J. Interferences during Analysis of Polyphenols in Fruit Juices; Second cycle, A2E; SLU Alnarp, Horticulture: Uppsala, Sweden, 2010.

31. Liem, D.G.; Miremadi, F.; Zandstra, E.H.; Keast, R.S.J. Health labelling can influence taste perception and use of table salt for reduced sodium products. Public Health Nutr. 2012, 15, 2340-2347. [CrossRef] [PubMed]

32. Sabbe, S.; Verbeke, W.; Deliza, R.; Matta, V.; Van Damme, P. Effect of a health claim and personal characteristics on consumer acceptance of fruit juices with different concentrations of acai (Euterpeoleracea Mart.). Appetite 2009, 53, 84-92. [CrossRef] [PubMed]

33. Kihlberg, I.; Johansson, L.; Langsrud, Ø.; Risvik, E. Effects of Information on liking of bread. Food Qual. Preference 2005, 16, 25-35. [CrossRef]

34. Astill, C.; Birch, M.; Dacombe, C.; Humphrey, P.G.; Martin, P. Factors affecting the Caffeine and Polyphenol Content of Black and Green Tea Infusions. J. Agric. Food Chem. 2001, 49, 5340-5347. [CrossRef] [PubMed]

35. Lee, J.; Chambers, D.; Chambers, E., IV. Sensory and Instrumental Flavor Changes in Green Tea Brewed Multiple Times. Foods 2013, 2, 554-571. [CrossRef] [PubMed]

36. Hicks, M.B.; Hsieh, P.Y.-H.; Bell, L.N. Tea preparation and its influence on methylxanthine concentration. Food Res. Int. 1996, 29, 325-330. [CrossRef] 